\title{
Evaluation of the groove for vertebral artery using CT angiography*
}

\author{
Ayşegül Furat ${ }^{1}$, Nurhan Erbil ${ }^{2}$, Rahşan Göçmen ${ }^{3}$ \\ ${ }^{\prime}$ Department of Anatomy, School of Medicine, Hacettepe University, Ankara, Turkey \\ ${ }^{2}$ Department of Biophysics, School of Medicine, Hacettepe University, Ankara, Turkey \\ ${ }^{3}$ Department of Radiology, School of Medicine, Hacettepe University, Ankara, Turkey
}

\begin{abstract}
Objectives: Groove for vertebral artery (sulcus arteriae vertebralis) is located on the posterior arch of the first cervical vertebra (atlas) where the vertebral artery passes over to reach the foramen magnum. The bony process between the posterior arch and the superior articulating process of the atlas is a common variation usually detected by lateral radiographies. This bony bridge is most commonly named as the ponticulus posticus. The aim of this study was to evaluate the existence of the ponticulus posticus and morphological features of the groove for vertebral artery.

Methods: We performed a retrospective analysis of the groove for vertebral artery from 347 head and neck CT angiographies (694 bilaterally) at the Department of Radiology, Hacettepe University School of Medicine.

Results: Complete ponticulus posticus incidence was found to be $12.1 \%$, and $27.38 \%$ of these were bilateral. Post-sulcus arterial dimensions were found to be narrower than the pre-sulcus dimensions of the vertebral artery if the ponticulus posticus was incomplete.

Conclusion: The groove for vertebral artery is a commonly studied variation among different nations and using different methods like lateral dental graphies, cadaveric studies and dry skulls. This study will be a guide for clinical problems like headache, vascular diseases and surgical interventions of the atlas in a very large patient population and using CT angiography, a sensitive method for visualizing this area.
\end{abstract}

Keywords: arcuate foramen; CT angiography; groove for vertebral artery; ponticulus posticus

Anatomy 2017;11(2):61-66 @2017 Turkish Society of Anatomy and Clinical Anatomy (TSACA)

\section{Introduction}

The groove for vertebral atery (sulcus arteriae vertebralis) is located on the first cervical vertebra (atlas, C1) where the vertebral artery passes over the posterior arch of atlas to reach the foramen magnum. A bony bridge between the posterior of the superior articular process and the posterolateral of the posterior arch of the atlas is a common variation that can be detected by radiographic images. This bony process encircles the groove for vertebral artery and the first cervical nerve partially or completely. It is known by numerous names such as ponticulus posticus (little posterior bridge, PP), Kimmerle's anomaly and Kimmerle's variant (Figure 1); PP is the most commonly used termi- nology. If PP exists, the sulcus can become a foramen which is known as arcuate foramen, foramen arcuale atlantis, sagittal foramen, retroarticular canal, retroarticular vertebral ring, atlantal posterior foramen or the upper retroarticular foramen. ${ }^{[1-7]}$ The causes of the PP remain debated, but it has been proposed to be linked to either an ossification of the posterior atlantooccipital ligament or a congenital anomaly. However, it is usually regarded as a simple variation of the atlas which is usually ignored by the physician. ${ }^{[8-11]}$ We may observe the PP in patients who do not have any evidence of a symptom in the craniocervical region. However, recent studies have suggested otherwise. The compression of nervous and vascular structures pass-

*This study was presented at the 7th Global Neurologists Annual Meeting on Neurology and Neurosurgery, Vienna, Austria (22-24 August 2016). 
Table 1

Distribution of the patients according to the degree of the PP, gender, age and laterality.

\begin{tabular}{|c|c|c|c|c|c|c|c|c|c|c|}
\hline \multirow[b]{3}{*}{ Degree of PP } & \multicolumn{5}{|c|}{ Left (mean) } & \multicolumn{5}{|c|}{ Right (mean) } \\
\hline & \multicolumn{2}{|c|}{ Female } & \multicolumn{2}{|c|}{ Male } & \multirow[b]{2}{*}{ Total } & \multicolumn{2}{|c|}{ Female } & \multicolumn{2}{|c|}{ Male } & \multirow[b]{2}{*}{ Total } \\
\hline & $<40 y$ & $>40 y$ & $<40 y$ & $>40 y$ & & $<40 y$ & $>40 y$ & $<40 y$ & $>40 y$ & \\
\hline 0 & $27(33.75 \%)$ & $34(34.34 \%)$ & $43(54.43 \%)$ & $21(23.60 \%)$ & $125(36 \%)$ & $26(32.50 \%)$ & $43(43.43 \%)$ & $38(48.10 \%)$ & $26(29.21 \%)$ & $133(38.3 \%)$ \\
\hline 1 & $23(28.75 \%)$ & $33(33.33 \%)$ & $18(22.78 \%)$ & $31(34.83 \%)$ & $105(30.3 \%)$ & $22(27.50 \%)$ & $30(30.30 \%)$ & $17(21.52 \%)$ & $30(33.71 \%)$ & $99(28.5 \%)$ \\
\hline 2 & $17(21.25 \%)$ & $12(12.12 \%)$ & $6(7.59 \%)$ & $16(17.98 \%)$ & 51 (14.7\%) & $17(21.25 \%)$ & 7 (7.07\%) & 7 (8.86\%) & $15(16.85 \%)$ & $46(13.3 \%)$ \\
\hline 3 & $10(12.50 \%)$ & $7(7.07 \%)$ & $0(0.00 \%)$ & $4(4.49 \%)$ & $21(6 \%)$ & $9(11.25 \%)$ & $7(7.07 \%)$ & $8(10.13 \%)$ & $6(6.74 \%)$ & 30 (8.7\%) \\
\hline 4 & $3(3.75 \%)$ & $13(13.13 \%)$ & $12(15.19 \%)$ & $17(19.10 \%)$ & $45(13 \%)$ & $6(7.5 \%)$ & $12(12.12 \%)$ & $9(11.39 \%)$ & $12(13.48 \%)$ & $39(11.2 \%)$ \\
\hline
\end{tabular}

ing through the foramen may cause many symptoms like vertebrobasilar insufficiency, cervical migraine, neuro-sensory type hearing loss, vertigo and arm/shoulder pain. It may cause dissections of the neurovascular structures or could also be asymptomatic. ${ }^{[3,5,12-14]}$ Nowadays, there has been an increase in the number of patients undergoing $\mathrm{C} 1$ lateral mass screw (C1LMS) operation..$^{[1,3,5-7,10,13,15-18]}$ If the patient suffers from PP, the placement of the screw could be difficult during these operations. ${ }^{[19]}$ Due to this clinical condition, it's important to understand the anatomy of the craniocervical region. PP is a common variation of this region and its presence must be carefully evaluated especially before the surgeries. This study aims to determine and analyze the existence of PP and correlate the dimensions of the vertebral artery with its prevalence.

\section{Materials and Methods}

We conducted a retrospective study using head and neck CT angiographies of 347 patients (694 bilaterally) admitted to the Department of Radiology in Hacettepe University School of Medicine for stroke and vascular problems between January 2010 and December 2015. Radiological images used in research were with patient consent with records kept in the Radiology Department of Hacettepe University Hospital. Head and neck CT angiography imaging was performed using a 64-slice Dual Source CT Scanner (Siemens Medical Systems,
Erlangen, Germany). We evaluated axial unprocessed and also sagittal and coronal reformatted images with 1 $\mathrm{mm}$ slice thickness. The images were evaluated for incidence, laterality, age and gender effect on the incidence of complete PP. The measurements for the dimensions of arcuate foramen and the vertebral artery were also conducted (Figure 2). For descriptive purposes, we divided the study groups into young ( $<40$ years), old ( $>40$ years), male and female. We also evaluated the groove for the vertebral artery according to the laterality (leftright and bilateral) and the degree of concavity of the groove for vertebral artery (scored between $0-4 ; 0$ : no PP; 1, 2, 3: incomplete PP presence; 4: complete PP presence) (Tables 1 and 2). The diameters of the vertebral artery were measured before the groove (defined as pre-sulcus), inside the groove (defined as in-sulcus) and after leaving the groove (defined as post-sulcus) (Figure 2). Image analysis and measurements were conducted using the PACS integrated 'centricity universal viewerversion 6' (GE Healthcare, Chicago, IL, USA). Once the measurements were completed, group comparisons were conducted using the paired samples t-test with Bonferroni correction. Correlations were statistically evaluated using the 'multivariate analysis of variance (MANOVA) test' using SPSS 15 (IBM Corporation, New York, NY, USA). Statistical significance was set at a $\mathrm{p}$ value less than 0.05 .

Table 2

Diameters of the vertebral artery around the sulcus (mean $\pm \mathrm{SD}, \mathrm{mm}$ ).

\begin{tabular}{|c|c|c|c|c|c|c|}
\hline \multirow[b]{2}{*}{ Gender } & \multicolumn{3}{|c|}{ Left } & \multicolumn{3}{|c|}{ Right } \\
\hline & Pre-sulcus & In-sulcus & Post-sulcus & Pre-sulcus & In-sulcus & Post-sulcus \\
\hline Female $(n=178)$ & $0.25 \pm 0.07$ & $0.27 \pm 0.07$ & $0.25 \pm 0.08$ & $0.25 \pm 0.07$ & $0.26 \pm 0.07$ & $0.26 \pm 0.08$ \\
\hline Male $(n=165)$ & $0.31 \pm 0.08$ & $0.29 \pm 0.08$ & $0.29 \pm 0.08$ & $0.31 \pm 0.07$ & $0.28 \pm 0.08$ & $0.29 \pm 0.08$ \\
\hline
\end{tabular}



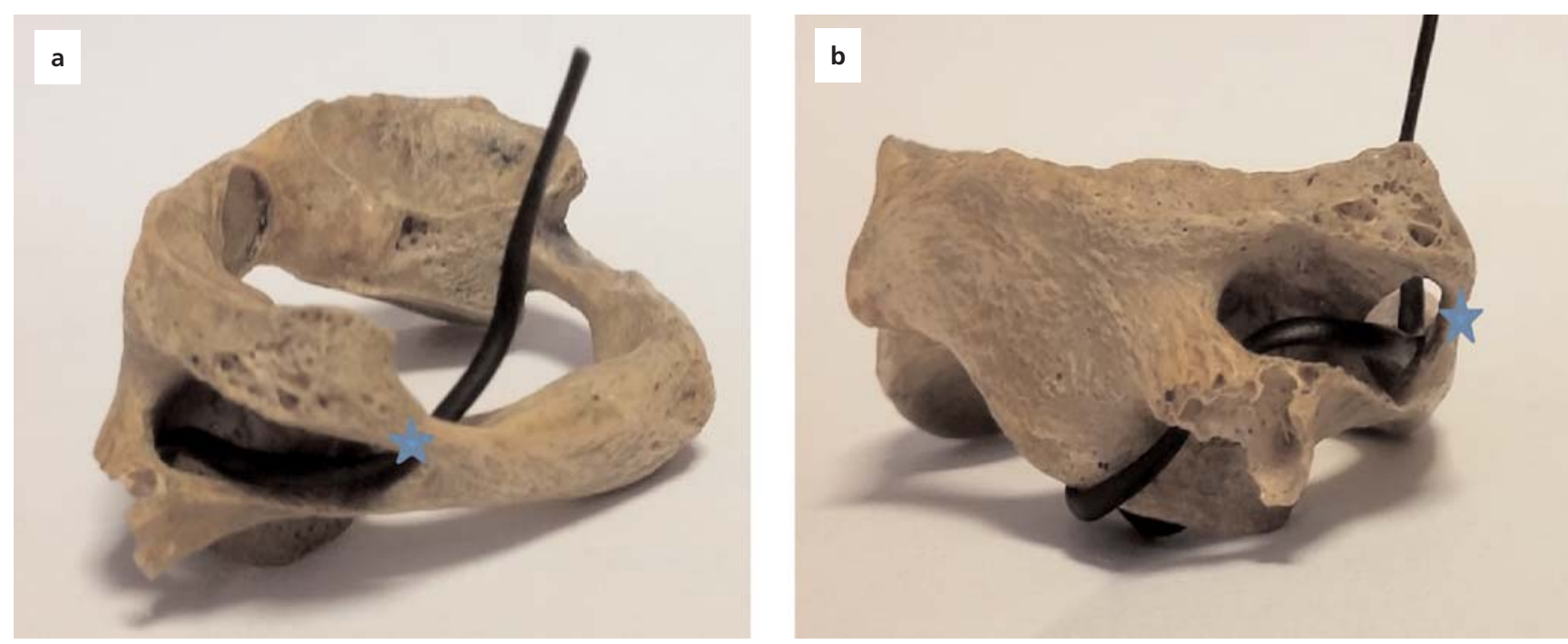

Figure 1. $(\mathbf{a}, \mathbf{b})$ Ponticulus posticus of atlas $\left(^{\star}\right)$. [Color figure can be viewed in the online issue, which is available at www. anatomy.org.tr]

\section{Results}

The study group composed of 165 males and 178 females with a mean age of $49 \pm 19$ (range: 14 to 87 ). We identified 84 patients with complete PP (Degree 4) which resulted in a prevalence of $12.1 \%$. Of these, $6.3 \%$ were bilateral; which constituted $27.38 \%$ of the complete PPs. The analysis of the left side of the PP revealed that $13 \%$ were complete (Degree 4 ) and $51 \%$ were incomplete (Degree 1, 2, 3). As shown in Table 1, evaluations of patients' right side resulted with $11.2 \%$ with a complete PP and $50.5 \%$ with an incomplete PP. Furthermore, our results suggested that the amount of complete PP did not substantially vary based on gender $(\mathrm{p}<0.383)$ or laterality $(\mathrm{p}<0.846)$.

The mean area of the arcuate foramen was $8.5 \mathrm{~mm}^{2}$ on the left side and $7 \mathrm{~mm}^{2}$ on the right side. We measured the diameter of the vertebral artery prior to entry into the groove, within the groove, and immediately after leaving the groove (Figure 2). Table 2 depicts the mean values and standart deviations. Our results indicated a significant difference of diameters of the vertebral artery in terms of laterality and gender (Table 2). The analysis of the vessel diameter for men and women indicated that the vessel diameter was significantly higher in
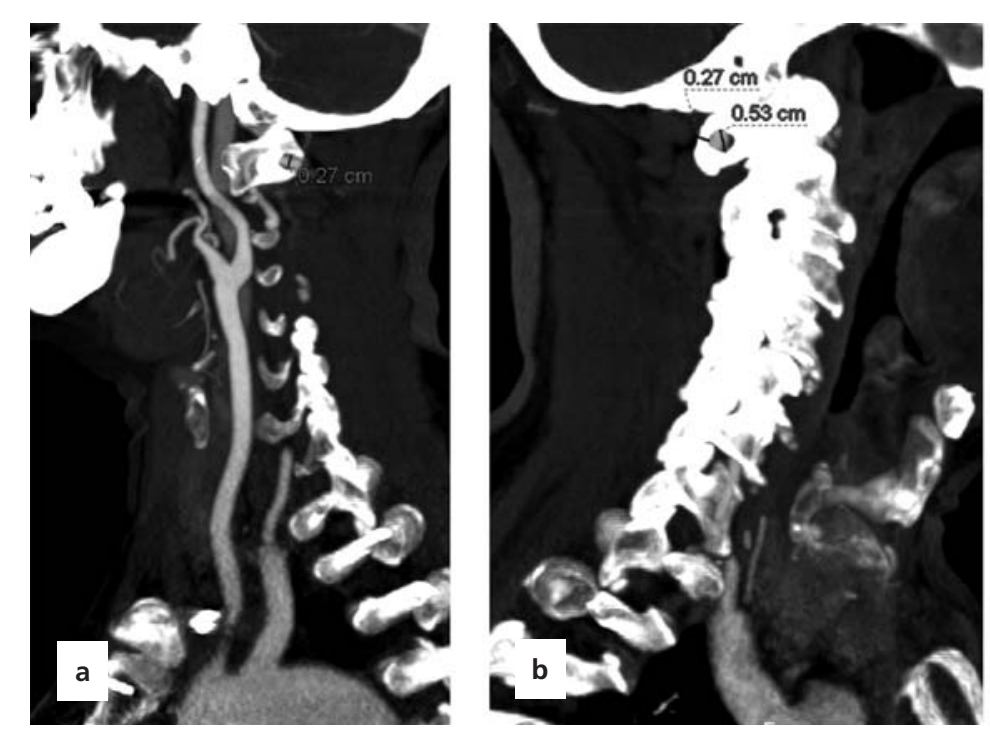

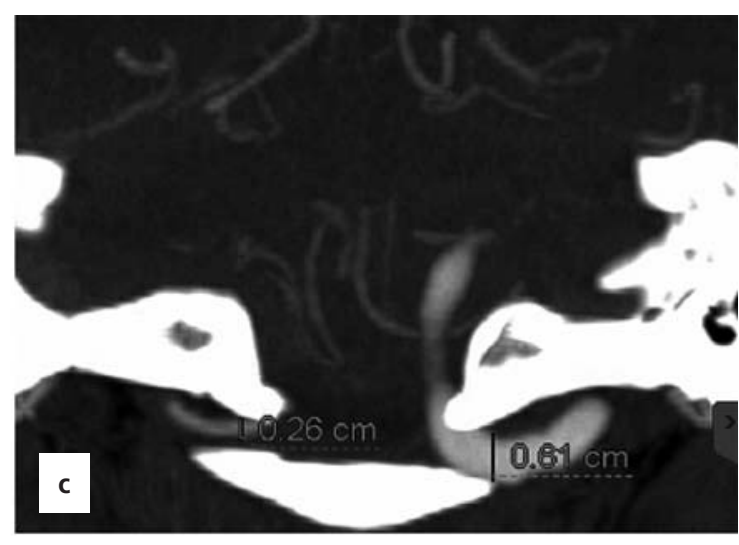

Figure 2. The diameter of Degree 2 PP (a) and complete PP (b) in lateral view, and diameter of the left and right vertebral artery after leaving the groove in coronal view (c). 
Table 3

Comparison of diameters of the vertebral artery according to gender and laterality using ANOVA.

\begin{tabular}{|c|c|c|c|c|c|c|}
\hline Side & Parameter & Comparison & Sum of squares & Mean square & $\mathbf{F}$ & $\mathrm{p}^{*}$ \\
\hline \multirow[t]{9}{*}{ Left } & Pre-sulcus vs. gender & Between groups & 0.345 & 0.345 & 62.07 & 0 \\
\hline & & Within groups & 1.897 & 0.006 & & \\
\hline & & Total & 2.242 & & & \\
\hline & In-sulcus vs. gender & Between groups & 0.075 & 0.075 & 14.48 & 0 \\
\hline & & Within groups & 1.768 & 0.005 & & \\
\hline & & Total & 1.843 & & & \\
\hline & Post-sulcus vs. gender & Between groups & 0.186 & 0.186 & 31.37 & 0 \\
\hline & & Within groups & 2.018 & 0.006 & & \\
\hline & & Total & 2.204 & & & \\
\hline \multirow[t]{9}{*}{ Right } & Pre-sulcus vs. gender & Between groups & 0.303 & 0.186 & 61.39 & 0 \\
\hline & & Within groups & 1.684 & 0.005 & & \\
\hline & & Total & 1.988 & & & \\
\hline & In-sulcus vs. gender & Between groups & 0.038 & 0.038 & 7.61 & 0.006 \\
\hline & & Within groups & 1.715 & 0.005 & & \\
\hline & & Total & 1.753 & & & \\
\hline & Post-sulcus vs. gender & Between groups & 0.066 & 0.066 & 11.14 & 0.001 \\
\hline & & Within groups & 2.016 & 0.006 & & \\
\hline & & Total & 2.082 & & & \\
\hline
\end{tabular}

${ }^{*} \mathrm{p}=0.05$

men on both sides $(\mathrm{p}<0$ on the left side and $\mathrm{p}<0.006$ on the right side (Table 3).

This difference can be attributed to the higher values of the vessel diameter for men (Table 2). In Degree 1, 2 and 3 groups, the vessel diameter significantly decreased after leaving the sulcus on both sides $(\mathrm{p}<0.028$ for the right side, $\mathrm{p}<0.001$ for the left side (Table 4). We did not find a statistically significant difference between the degree of the PP and vessel diameter in terms of laterality. The mean diameter of the arcuate foramen was 0.33 $\mathrm{cm}$ on the left side and $0.30 \mathrm{~cm}$ on the right side. The mean thickness of the PP was $0.2 \mathrm{~cm}$ on the left side and $0.22 \mathrm{~cm}$ on the right side. Substantial variations were not evident for the thickness and diameter of the PP.

\section{Discussion}

A literature review revealed that multiple studies e produced different results in regard to the incidence of the PP (1.14-37\%) (Table 5). Elliot and Tanweer ${ }^{[7]}$ substantially contributed to the understanding of radiologists, anatomists and neurosurgeons by reviewing and analyzing radiographic, cadaveric and surgical databases. This examination reported the prevalence of complete PP as 44\% from an on-line database of 21,789 cases, which has included 15,542 patients and 6247 body and cadaver samples. They found the the prevalence of complete PP as $9.3 \%$, while incomplete PP had a prevalence of $8.7 \%$. In
$5.4 \%$ of their cases, the PP was bilateral. Furthermore, this examination did not confirm a statistical correlation to gender. Bayrakdar et al. ${ }^{[2]}$ conducted another study that analyzed 730 cone beam computed tomography (CBCT) images, which found PP in 127 patients (17\%). Males had a prevalence of $19.5 \%$ (54 of 277 patients) and females a prevalence of $16.1 \%$ (73 of 453 patients).

Sharma et al. ${ }^{[17]}$ investigated lateral cephalometric radiographs of 858 Indian orthodontic patients for the presence of PP. In this study, complete PP prevalence was $4.3 \%$ with a male predominance of $5.33 \%$. In lateral cephalometric radiographies of 353 Caucasion patients,

Table 4

Comparison of diameters of the vertebral artery according to the degree of the PP and laterality.

\begin{tabular}{lllll}
\hline & & $\mathbf{n}$ & Mean \pm SD $(\mathbf{c m})$ & $\mathbf{p}$ \\
\hline \multirow{2}{*}{ Degrees 1, 2, 3 } & Left & 296 & $0.278 \pm 0.083$ & 0.001 \\
& & 296 & $0.268 \pm 0.081$ & \\
\cline { 2 - 5 } & Right & 296 & $0.282 \pm 0.077$ & 0.028 \\
& & 296 & $0.276 \pm 0.076$ & \\
\hline \multirow{2}{*}{ Legree 4 } & Left & 86 & $0.277 \pm 0.069$ & 0.254 \\
& & 86 & $0.273 \pm 0.075$ & \\
\cline { 2 - 5 } & Right & 86 & $0.27 \pm 0.078$ & 0.405 \\
& & 86 & $0.268 \pm 0.089$ & \\
\hline
\end{tabular}


Kendrick and Biggs ${ }^{[10]}$ demonstrated a $15.8 \%$ prevalence of PP with no difference between men and women.

The majority of previous studies used lateral radiographies to identify PP, but this technique is not suitable for determining the laterality of the PP. Therefore, head and neck CT angiographies should be considered for evaluating the cervical region. Our study is one of the first examinations to evaluate the presence of PP and its relation with the arterial dimensions in the Turkish population using the CT angiography technique. We evaluated 347 head and neck CT angiographies which demonstrated a prevalence of complete PPs of $12.1 \%$ with no variation due to gender or laterality. This result should be considered extremely beneficial for daily clinical practice. Therefore, this region should be carefully examined especially before screw placement operations in order to avoid injury to the vertebral artery. The examination of $\mathrm{PP}$ is also important for neck pain, headaches, visual disturbances, speech and swallowing problems, vertigo and vascular problems. Considering these clinical problems, we examined the correlation of the vessel morphometry to the occurence of PP. This was the first detailed examination of the vertebral artery around the sulcus. Our results showed that the mean vessel diameter was higher in men for both sides. We did not statistically confirm the difference between the degree of PP and vessel diameter on both sides. In incomplete PP cases, the decrease in diameter of the vessel on both sides was been statistically confirmed. $\mathrm{PP}$ and arcuate foramen should not be considered as a simple anatomical variations. The change in the diameter of the vessel due to incomplete PP may cause many clinical problems such as vertebrobasilar insufficiency. Clinical coexistence of PP with headache, neck pain, and vascular problems should also be studied. Compression of the first cervical nerve may also result in clinical sypmtoms. Therefore, such morphological evaluations should be of interest to both anatomists and clinicians. Compression of the neurovascular structures passing through the foramen may result in a combination of symptoms.

A limitation of our study was that the patient group was selected from a symptomatic stroke and vascular diseases patients who applied to our third level university hospital. Further studies with asymptomatic subjects, cadavers and dry bones are recommended to declare the differences among populations and nations.

Split and Sawresevicz-Rybak ${ }^{[12]}$ found that headache, neck, shoulder, and arm pains as well as vertigo was significantly higher in patients with complete PP than those with partial PP. A complete PP may be mistaken for a broad dorsal arch and the surgeon may accidentally insert the screw into the arcuate foramen which can result in
Table 5

Incidence of complete PP in the literature and current study. $[2,3,6-6,14,15,17,20-22]$

\begin{tabular}{|c|c|c|}
\hline Author & Material & $\begin{array}{c}\text { Incidence of } \\
\text { complete PP (\%) }\end{array}$ \\
\hline Lamberty and Zivanovic, $1973^{[14]}$ & Dry bones & 7.5 \\
\hline Lamberty and Zivanovic, $1973^{[14]}$ & Radiography & 15 \\
\hline Dhall et al., $1993^{[6]}$ & Dry bones & 37.83 \\
\hline Hasan et al., $2001^{[8]}$ & Dry bones and cadaver & 1.14 \\
\hline Cakmak et al., $2005^{[3]}$ & Dry bones & 11.7 \\
\hline Paraskevas et al., $2005^{[15]}$ & Dry bones & 10.23 \\
\hline Tubbs et al., $2007^{[21]}$ & Cadaver & 5 \\
\hline Kim et al., $2007^{[22]}$ & $\mathrm{CT}$ & 26 \\
\hline Kim et al., $2007^{[22]}$ & Radiography & 14 \\
\hline Sharma et al., $2010^{[17]}$ & Radiography & 4.3 \\
\hline Simsek et al, 2008 ${ }^{[2]]}$ & Dry bones & 3.8 \\
\hline Elliott and Tanweer, 2014 & Cadaver & 18.8 \\
\hline Elliott and Tanweer, 2014 & $\mathrm{CT}$ & 17.2 \\
\hline Elliott and Tanweer, 2014 ${ }^{[7]}$ & Radiography & 16.6 \\
\hline Bayrakdar et al., 2014 ${ }^{[2]}$ & Cone beam $\mathrm{CT}$ & 17.4 \\
\hline Firat et al., 2017 & CT angiography & 12.1 \\
\hline
\end{tabular}

damage to the vertebral artery and lead to stroke or death due to thrombosis, embolism, or arterial dissection. ${ }^{[19]}$ Cushing et al..$^{[5]}$ observed arcuate foramen in eight of eleven patients with vertebral artery dissection and occlusion. The arterial injury was at the level of this anatomical variation in all cases. Since over $50 \%$ of head rotation occurs at the atlantoaxial joint, the vertebral artery is vulnerable to compression and stretching at this level and thus, additional compression/tethering due to an arcuate foramen can compound its predisposition to injury. During neck flexion, the vertebral artery glides superiorly and anteriorly relative to the posterior arch, which has a greater rate of occurence at the level of the lateral masses of the atlas compared to more caudal sites in the neck. ${ }^{[16]}$

The clinical significance of PP still remains unclear. Some scholars, such as Wight et al., ${ }^{[13]}$ identified correlations between PP and head pain and noted a significant overrepresentation of the ring in chiropractic patients with headaches without aura (i.e. visual or auditory disturbances). Surgical excision of the PP alleviates headache, vertigo, and basilar insufficiency. ${ }^{[18]}$ Spinal manipulative therapy involving craniovertebral articulation also alleviates symptoms of vertigo, headaches, and nausea ${ }^{[9,13]}$ Chiropractic treatments significantly improve the treatment of migraines. In addition, the results of this study may also be relevant to manual therapists, such as chiropractors, physical therapists, or other health care providers. If $\mathrm{PP}$ is detected or suspected, it must be documented in the the health record of the patient and a specialist consultation must be sought. 


\section{Conclusion}

Based on the findings in the present study, an incomplete arcuate foramen may compress the vertebral artery. The literature review reveals that the symptomatic compression of the vertebral artery at this location may be alleviated for some patients using decompressive procedures. Arcuate foramen is an anatomical variation that the neurosurgeons should consider when undertaking surgery near or on the posterior atlas. Our results confirm that the prevelance of $\mathrm{PP}$ is a common variation, although its prevalence in other groups remains to be investigated.

\section{Acknowledgement}

This study was funded by the Hacettepe University Scientific Research Unit with project number THD-20169170.

\section{References}

1. Ahmad FU, Wang MY. Lateral mass of $\mathrm{C} 1$ fixation and ponticulusposticus. World Neurosurg 2014;82:E145-6.

2. Bayrakdar IS, Miloglu O, Altun O, Gumussoy I, Durna D, Yilmaz $\mathrm{AB}$. Cone beam computed tomography imaging of ponticulus posticus: prevalence, characteristics, and a review of the literature. Oral Surg Oral Med Oral Pathol Oral Radiol 2014;118:E210-9.

3. Cakmak G, Gurdal E, Ekinci G, Yildiz E, Cavdar S. Arcuate foramen and its clinical significance. Saudi Med J 2005;26:1409-13.

4. Chen $\mathrm{CH}$, Chen $\mathrm{YK}$, Wang CK. Prevalence of ponticuli posticus among patients referred for dental examinations by cone-beam CT. Spine J 2015;15:1270-6.

5. Cushing KE, Ramesh V, Gardner-Medwin D, Todd NV, Gholkar A, Baxter P, Griffiths PD. Tethering of the vertebral artery in the congenital arcuate foramen of the atlas vertebra: a possible cause of vertebral artery dissection in children. Dev Med Child Neurol 2001;43:491-6.

6. Dhall U, Chhabra S, Dhall JC. Bilateral asymmetry in bridges and superior articular facets of atlas vertebra. J Anat Soc India 1993;42: $23-7$.

7. Elliott RE, Tanweer O. The prevalence of the ponticulus posticus (arcuate foramen) and its importance in the goel-harms procedure: meta-analysis and review of the literature. World Neurosurg 2014;82:E335-43.
8. Hasan M, Shukla S, Siddiqui MS, Singh D. Posterolateral tunnels and ponticuli in human atlas vertebrae. J Anat 2001;199:339-43.

9. Kavakli A, Aydinlioglu A, Yesilyurt H, Kus I, Diyarbakirli S, Erdem S, Anlar O. Variants and deformities of atlas vertebrae in Eastern Anatolian people. Saudi Med J 2004;25:322-5.

10. Kendrick GS, Biggs NL. Incidence of ponticulus posticus of first cervical vertebra between ages 6 to 17. Anat Rec 1963;145:449-53.

11. Kim MS. Anatomical variant of atlas: arcuate foramen, occipitalization of atlas, and defect of posterior arch of atlas. J Korean Neurosurg Soc 2015;8:528-33.

12. Split W, Sawrasewicz-Rybak M. Character of headache in Kimmerle anomaly. Headache 2002;42:911-6.

13. Wight S, Osborne N, Breen AC. Incidence of ponticulus posterior of the atlas in migraine and cervicogenic headache. J Manipulative Physiol Ther 1999;22:15-20.

14. Lamberty BG, Zivanovic S. The retro-articular vertebral artery ring of the atlas and its significance. Acta Anat 1973;85:113-22.

15. Paraskevas G, Papaziogas B, Tsonidis C, Kapetanos G. Gross morphology of the bridges over the vertebral artery groove on the atlas. Surg Radiol Anat 2005;27:129-36.

16. Sekerci AE, Soylu E, Arikan MP, Ozcan G, Amuk M, Kocoglu F. Prevalence and morphologic characteristics of ponticulus posticus: analysis using cone-beam computed tomography. J Chiropr Med 2015;14:153-61.

17. Sharma V, Chaudhary D, Mitra R. Prevalence of ponticulus posticus in Indian orthodontic patients. Dentomaxillofac Radiol 2010;39:277-83

18. Vernon H. Cervicogenic headache. In: Gatterman MI, editor. Foundations of the chiropractic subluxation. St Louis (MO): Mosby 1995;306-16.

19. Young JP, Young PH, Ackermann MJ, Anderson PA, Riew KD. The ponticulus posticus: implications for screw insertion into the first cervical lateral mass. J Bone Joint Surg Am 2005;87:2495-98.

20. Simsek S, Yigitkanli K, Comert A, Acar HI, Seckin H, Er U, Belen D, Tekdemir I, Elhan A. Posterior osseous bridging of C1. J Clin Neurosci 2008;15:686-8.

21. Tubbs RS, Johnson PC, Shoja MM, Loukas M, Oakes WJ. Foramen arcuale: anatomical study and review of the literature. J Neurosurg Spine 2007;6:31-4.

22. Kim KH, Park KW, Manh TH, Yeom JS, Chang BS, Lee CK. Prevalence and morphologic features of ponticulus posticus in Koreans: analysis of 312 radiographs and 225 three-dimensional CT scans. Asian Spine J 2007;1:27-31.

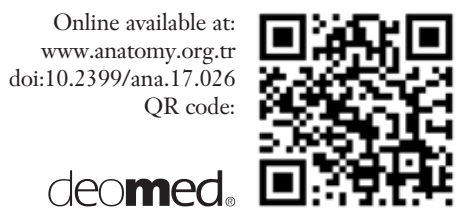

Correspondence to: Ayşegül Firat, MD
Department of Anatomy, School of Medicine,
Hacettepe University, Ankara, Turkey
Phone: +90 3123052132
e-mail: aysfirat@hacettepe.edu.tr
Conflict of interest statement: No conflicts declared.

This is an open access article distributed under the terms of the Creative Commons Attribution-NonCommercial-NoDerivs 3.0 Unported (CC BY-NCND3.0) Licence (http://creativecommons.org/licenses/by-nc-nd/3.0/) which permits unrestricted noncommercial use, distribution, and reproduction in any medium, provided the original work is properly cited. Please cite this article as: Firat A, Erbil N, Göçmen R. Evaluation of the groove for vertebral artery using CT angiography. Anatomy 2017;11(2):61-66. 